ECCOMAS

Proceedia $8^{\text {th }}$ ECCOMAS Thematic Conference on Computational Methods in Structural Dynamics and Earthquake Engineering

M. Papadrakakis, M. Fragiadakis (eds.) Streamed from Athens, Greece, 28 - 30 June 2021

\title{
INVESTIGATION OF THE RESPONSE OF INTERFACES OF CFRP SHEET STRENGTHENING SCHEMES ENHANCED WITH TOUGHENED EPOXY ADHESIVE LAYERS APPLIED IN CORRODED CONCRETE SUBSTRATES.
}

\author{
Dimitra V Achillopoulou ${ }^{1,2}$ \\ ${ }^{1}$ University of Surrey, Guildford, UK \\ d.achillopoulou@surrey.ac.uk \\ ${ }^{2}$ Democritus University of Thrace, Xanthi, Greece \\ dimiachi@civil.duth.gr
}

\begin{abstract}
:
This paper studies the behavior of enhanced strengthening Carbon Fiber Reinforced Polymer (CFRP) strengthening schemes. The CFRP systems are bonded to concrete substrates using toughened adhesive layers to limit the failure propagation in the interface and its brittle nature. Due to the importance of the integrity of the substrate two different scenarios are examined experimentally and analytically: healthy concrete and with corrosion products leached by the corroded reinforcement. The modified shear behavior (stress, slip) of the interfaces between concrete and CFRPs was investigated with a double shear test configuration. The corrosion products leached on the external layers of the substrate affected the interface response of the strengthening scheme, resulting in lower rates of shear stresses corresponding to lower slip ratios. The analysis of the sliding and shear stress distribution along the interface has also been investigated locally by finite elements using a cohesive model (CM) to examine the propagation of failure at the interface length. Toughened adhesives limit the substrate's dislocations and shift the response of the interface from pure elastic to pseudo-ductile in distinct stages. The debonding mode (brittle or pseudo-ductile) depends heavily on the toughness of the adhesive and its tensile modulus, since the higher the modulus is, the more brittle the response becomes.
\end{abstract}

Keywords: CFRPs, corrosion, strengthening schemes, adhesive layers, toughness, efficiency

ISSN:2623-3347 (c) 2021 The Authors. Published by Eccomas Proceedia.

Peer-review under responsibility of the organizing committee of COMPDYN 2021.

doi: $10.7712 / 120121.8825 .19454$ 


\section{INTRODUCTION}

In the past few decades, there is a boost in the technological advancement of structural solutions with various strengthening schemes developed for reinforced concrete (RC) members. Bonded composites, that is Fiber Reinforced Polymers (FRPs) made of glass, carbon or other kinds of fibers is a commonly used type. It is commonly accepted that the efficiency of the retrofitting measures is mainly based on the connection of the concrete substrate and the composite [1]. As such, the integrity of the substrate and the connection layer of the strengthening measure are the key elements to a successful intervention.

The use of FRPs orientates towards enhancing the deformability of the strengthened structural members since this type of retrofitting measures are not used to increase the stiffness of a structural member. They are applied on an adhesive layer, which fulfils the requirements of international standards, e.g. EN 1504-4 [2]. Standard epoxy adhesives normally show high tensile modulus and result in brittle fracture of the matrix. The main goal of this research paper is the explanation of the interfacial response of FRP and concrete substrate. FRP measures investigated are enhanced using toughened adhesive layers, which have a lower stiffness matrix and permit higher fracture energy.

This research examines, experimentally and analytically with finite element models (FEM), the use of toughened epoxy adhesive layers as part of strengthening schemes for RC members and has a focus on the examination of the limitation of the substrate's failure propagation due to the use of enhanced retrofitting systems. The toughened adhesives are expected to absorb more energy before debonding, especially under dynamic loads [3], [4]. The interaction with the concrete substrate to the dislocations imposed is examined with double-lap shear tests in carbon FRP (CFRPs) applied to concrete prisms.

Finally, the effectiveness of the bond behavior of these layers is also dependent on the concrete substrate integrity. As structures are exposed to various and at times extreme environmental conditions, the corrosion effect is usually met and has a tremendous impact on the structural integrity of the existing structures. As such, strengthening such members is challenging. A commonly accepted practice in these cases is, first, to define the corrosion rate and then to substitute the concrete substrate with a new one. In cases that the corrosion rate is low, and the bond behavior of concrete is within acceptable limits, strengthening measures can be directly applied. This paper also examines the influence of the corrosion products on the interface response of CFRP measures applied with toughened adhesive layers.

\section{EXPERIMENTAL INVESTIGATION}

For the purposes of the study, an experimental campaign has been designed. The campaign has two phases: a) accelerated corrosion procedure and b) double lap testing. The wider experimental campaign includes three different commercialized FRP systems (fabrics, laminates, Near Surface Mounted bars-NSM) applied in a healthy and corroded concrete substrate using three different adhesive layers, two of which are toughened. In this paper, the specimens including FRP fabrics are presented.

\subsection{Materials}

Nine concrete blocks with dimensions $150 \times 150 \times 250 \mathrm{~mm}$ were prepared according to [5], [6], [7] with 28-day compressive strength of $37.5 \mathrm{MPa}$ corresponding to a tensile strength of $3 \mathrm{MPa}$. All blocks contained steel rebar $\left(f_{\mathrm{sy}}=500 \mathrm{MPa}\right)$ of $18 \mathrm{~mm}$ diameter in the middle of the crosssection placed longitudinally to the concrete block. CFRP sheets (SikaWrap: density $\rho=1.8$ $\mathrm{kg} / \mathrm{L}$, tensile strength $\sigma_{u}=4900 \mathrm{MPa}$, modulus of elasticity $E_{0.05-0.25 \%}=230 \mathrm{GPa}$, tensile strain $\varepsilon_{E A B}=1.7 \%$ ) were bonded symmetrically on opposite sides of the concrete blocks at a bond 
length of $200 \mathrm{~m}$. The fibre orientation was $0^{\circ}$ along the longitudinal direction of concrete blocks. The systems were applied with a dry lay-up process and according to the technical specification of the manufacturer. The interfaces were treated properly to have a laitance contaminant-free, open-textured surface and were cleaned with air pressure to remove loose material, dust and rust. The two components' epoxy adhesives (Table 1) were mixed according to the manufacturer's recommended ratio and time (4:1 for Sikadur 330 and 100:74 for Sikadur 370). The composites are left to cure at ambient conditions $\left(20^{\circ} \mathrm{C}, 50 \%\right.$ relative humidity-RH) for at least a week before testing.

\begin{tabular}{|c|c|c|c|c|}
\hline type & density $\rho[\mathrm{kg} / \mathrm{L}]$ & $\begin{array}{l}\text { tensile strength } \sigma_{u} \\
{[\mathrm{MPa}]}\end{array}$ & $\begin{array}{l}\text { E-modulus } \\
(0.05-0.25 \%)[\mathrm{GPa}]\end{array}$ & $\begin{array}{l}\text { tensile strain } \varepsilon(\mathrm{EAB}) \\
{[\%]}\end{array}$ \\
\hline Sikadur 330 & $\sim 1.4$ & 29 & 4000 & 1 \\
\hline Sikadur 370 & -1.7 & 30 & 5000 & 2.5 \\
\hline
\end{tabular}

Table 1: Mechanical properties of epoxy adhesive layers.

\subsection{Accelerated corrosion}

The concrete prisms were exposed to wet conditions in a tank. They were bathed in a $3.5-5 \%$ weight NaCl-water solution (Figure 1a), which covered one third of the cross-section size of the concrete blocks [8], [9]. A low ratio of corrosion of the steel rebar cross-section is created almost equal to $6 \%$ with a continuous power supply $(\approx 1 \mathrm{~mA})$ [9] wired in the steel rebars for about three weeks.

\subsection{Experimental configuration}

Various experimental setups of double lap tests exist in the international literature [10]. These configurations permit the direct examination of the shear stresses of the interface. This study adopts a modified double lap shear test (Figure 1b). The concrete block lays on hollow support that permits slip and is hanged from the gripped ends of the FRPs that are fixed to a rigid steel frame. This alteration of the classic setup with two concrete blocks limits the relative slips of the interfaces of the different blocks, eliminates slips at the gripped ends of the FRP and at the same time permits direct shear stress measurement. The tests were performed on a compression machine at a speed of $1 \mathrm{~mm} / \mathrm{min}$ at room temperature $\left(20^{\circ} \mathrm{C}\right)$. The measurements of the deformation of the central part of the CFRP were recorded using a high accuracy laser sensor. Also, two Linear Displacement Transducers (LDVT) with a maximum capacity of $100 \mathrm{~mm}$, were used to measure the displacement of the upper level of the concrete block and the grips.

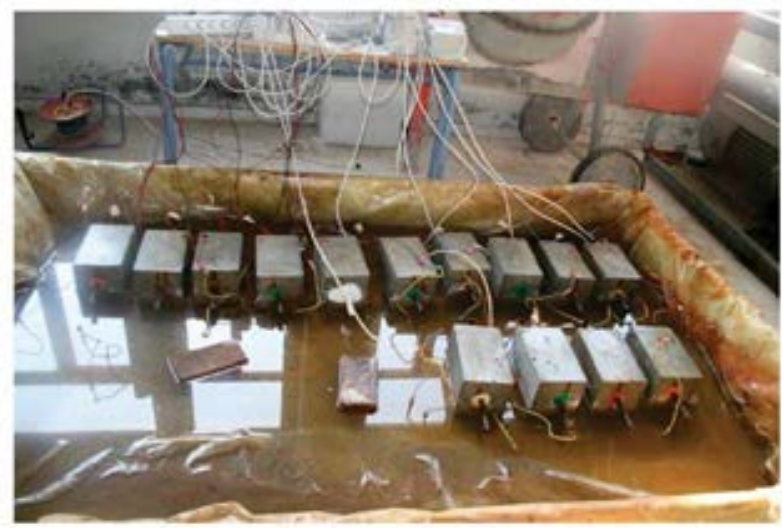

(a)

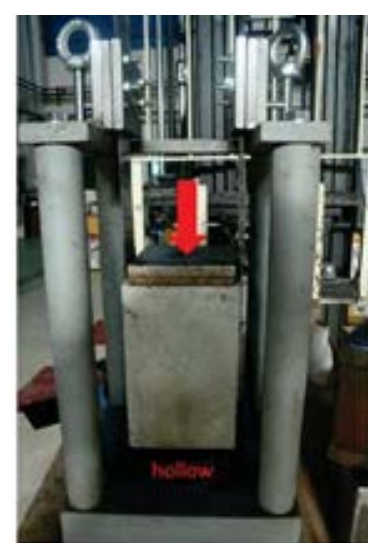

(b) 
Figure 1: Experimental campaign: a) accelcrated corrosion, b) double lap (DL) setup.

\section{FINITE ELEMENT SIMULATION}

Except for the experimental investigation, a numerical study was conducted in order to study locally the overloading, the response, initiation and propagation of failure of the interface. The debonding of FRP composites applied to the concrete substrate was simulated with a numerical model developed using the commercial software ANSYS. For the realistic representation and simulation of the failure modes of CFRP strengthened concrete substrates a bilinear cohesion zone model (CZM) fracture model was used and calibrated from the experimental results [11]. Concrete and CFRPS were treated as homogeneous isotropic linear-elastic materials and were connected through zero thickness interfaces. Concrete and composites were simulated using a $3 \mathrm{~d}$ solid element, defined by eight nodes having three degrees of freedom at each node (translations in the nodal $\mathrm{x}, \mathrm{y}$, and $\mathrm{z}$ directions).

\section{RESULTS}

\subsection{Experimental results}

The results are presented in shear stress- shear deformation diagrams of the average curves for the two categories of specimens, healthy and corroded, with both adhesive layers. Table 2 contains the characteristic values of the experimental results and the average curves.

Specimens wrapped with fabrics (H1330_1-3, Cr330_1-3) of unidirectional carbon fibers applied with the epoxy adhesive layer 330 present a response in three distinct stages, shown in Figure 2a. The toughened epoxy layers limit the substrate's failure propagation, allow the fracture to happen in stages and absorb more energy before debonding.

In the first stage the fabric is tensed (Stage I: linear elastic) at a linear rate. The fibers' configuration of the sheets is unidirectional and in parallel to the loading direction. This prevents bridging the crack propagation. In the second stage, there is a progressive crack initiation of the epoxy layer leading to crack opening, followed by a non-linear elastic yielding branch up to the transition point (Stage II: non-linear elastic yielding). The transition point ( $\left.\tau^{\text {trans }}, \gamma^{\text {trans }}\right)$ practically corresponds to the further propagation of the crack pattern from the resin to the substrate and the overall connection of the two materials. The third stage is characterized by major cracking both at the adhesive layer and the substrate. Plastic regions are created at the concrete, and especially at the initial debonding area at a distance of $5 \mathrm{~cm}$ from the loading end. At the ultimate point of this stage (Stage III: major cracking), the specimens exhibit debonding of the FRP $\left(\tau^{\mathrm{u}}, \gamma^{\mathrm{u}}\right)$. The failure mode is mainly caused due to the spalling of concrete at the delamination propagation area after the $5 \mathrm{~cm}$ and no FRP rupture is met (Figure 2c).

Figure $2 \mathrm{~b}$ also shows the effect of corroded steel rebars on the interface response. The green dashed line represents the average curve of specimens with corroded steel rebar with fabrics applied on the concrete substrate with epoxy adhesive layer 330, whereas the red solid line represents the average curve of the healthy specimens containing the same epoxy. There is a clear difference in the response in both cases. The interface of the corroded substrate (330_corroded_ave) containing corrosion products presents a 20\% decrease in shear strength $\left(\tau^{\bar{u}}\right)$ and $24 \%$ lower shear deformation $\left(\gamma^{\mathrm{u}}\right)$ at the ultimate point (Table 2). Also, the transition point is shifted to lower values of deformations $(52 \%)$ and strength (18\%). The leached corrosion products laying on the sides of the concrete substrate and the minor strains due to the initiation of corrosion are practically mass disturbance creating regions of altered consistency and resistance. Also, even in such low percentages of corrosion, which corresponds to corrosion initiation and to allowable bond values of the substrate, the crack initiation in the concrete mass in 
combination with the rust laying on the interface, makes the connection with the FRP strengthening scheme weaker and results in lower values of slip and shear strength.

A higher stiffness matrix corresponding to the specimens with sheets applied with epoxy adhesive layer 370 (Sikadur370) presents a different response (H1370_1-3, Table 2). Figure 2b shows that the tougher the epoxy resin matrix is, the stages II and II coincide. This means that even though there is a distinct transition point in almost the same levels of shear deformations but in higher values of shear stresses, the crack pattern both in the substrate and in the adhesive layer propagates simultaneously up to the debonding point of the strengthening system. The intrinsic toughened adhesive layer 370 is designed for steel substrates and especially suitable for fatigue cracking applications [4]. The crack width in the cases of concrete substrates is bigger than fatigue cracking in steel substrates. In combination with the stiffness of the matrix, the response alters from pseudo-plastic (case of Sikadur 330) to brittle.

\subsection{Finite element results}

The finite element simulations' results were calibrated with the corresponding tests. Figure 3 a shows the total stresses concentrated at the interface area between the concrete substrate and the FRP sheet. The stresses present a similar value in both cases, that is healthy and corroded substrates. Both cases, have a concentration of stresses near the loading end, presenting similar failure modes. Figure $2 \mathrm{c}$ show the differences of the failures and agree with the plastification mechanism of concrete and the sliding distance of the interface, of the FEM simulations' results presented in Figure $3 \mathrm{a} \& \mathrm{~b}$. It is also remarkable that the active length of the interface, meaning the length which concentrates the highest ratios of stresses, is $5 \%$ lower in the case of the corroded specimen.

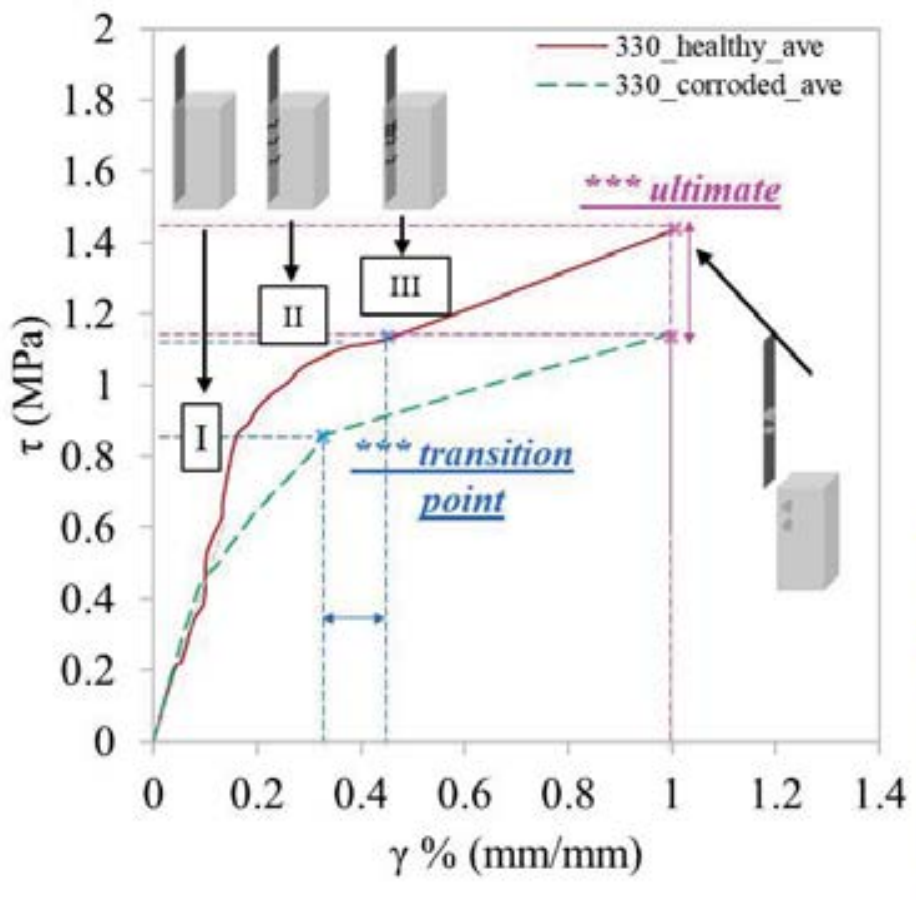

(a)
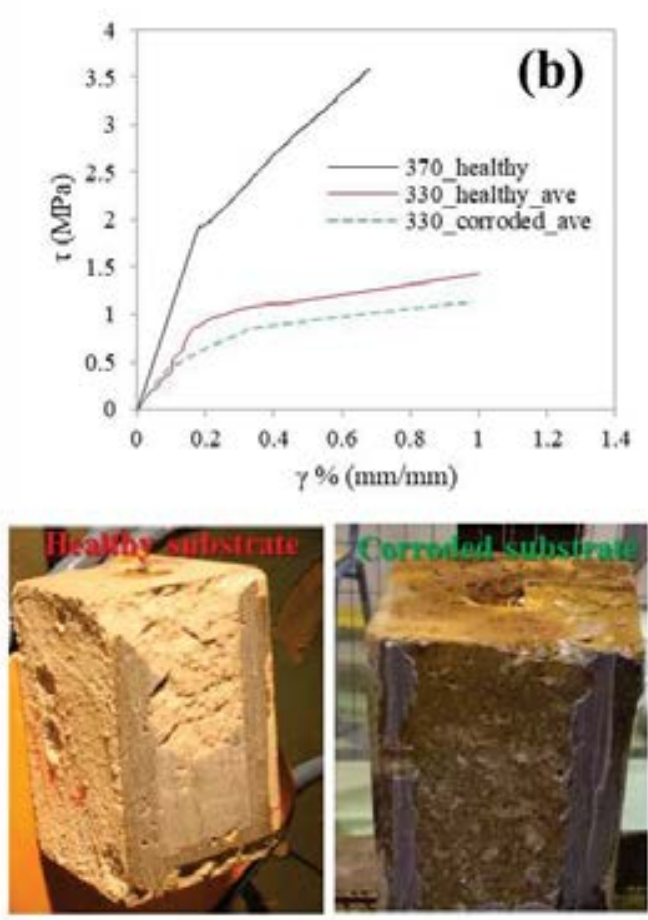

(c)

Figure 2: Experimental results of the DL tests: a), b) shear stress vs shear deformation curve, c) failure mode. 


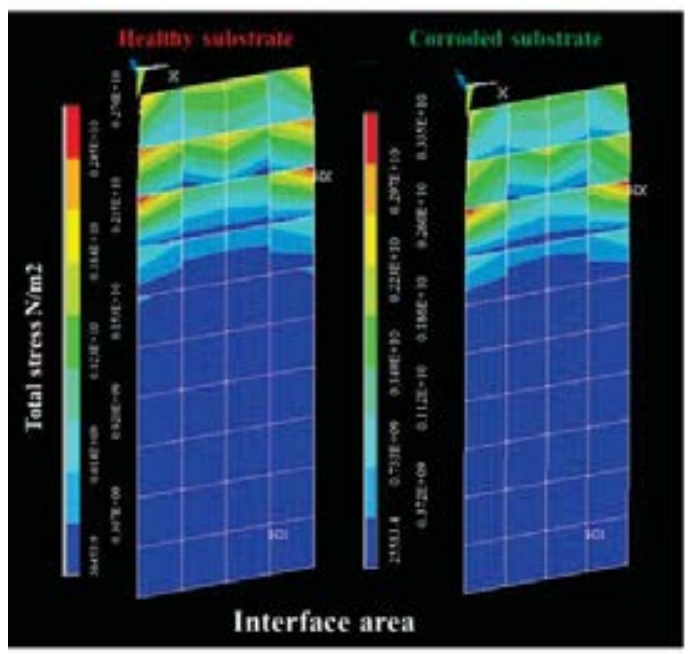

(a)

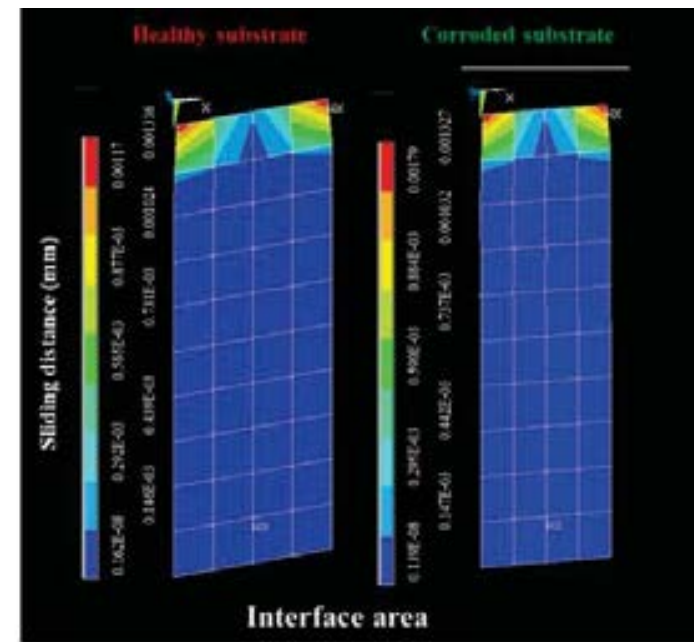

(b)

Figure 3: Contour plots of the interface a) total stresses, b) sliding distance.

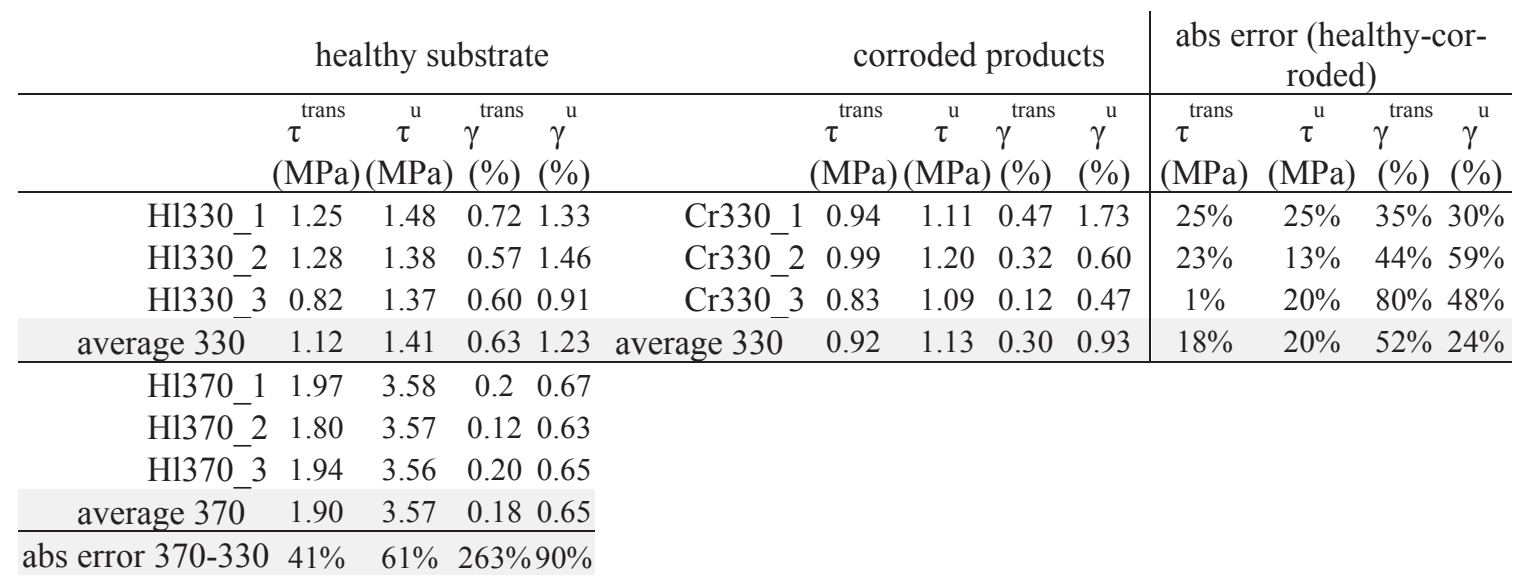

Table 2: Experimental results.

\section{CONCLUSIONS}

- Toughened adhesive layers shift the interface response in comparison with the standard epoxy commonly used, from brittle to pseudo-ductile in distinct stages. The more tough the adhesive layer is, the shorter are the stages before the failure of the wrapped CFRPs.

- The distinct stages of the response of interfaces denote a progressive failure and correspond to the crack propagating stages up to failure.

- The corrosion products affect the interface response. They provoke a decrease of approximately $20 \%$ of the ultimate shear strength and corresponding shear deformation, whereas the transition point is met in almost half the shear deformation.

- The length of the CFRP which is overloaded and hence activated, is almost $40 \%$ of the total length, whereas, in the case of leached corrosion at the interface, the active length is $5 \%$ lower. The majority of stresses are concentrated at a distance of $5 \mathrm{~cm}$ of the loading end provoking spalling of the concrete's substrate. 


\section{ACKNOWLEDGEMENTS}

This study has received funding from the European Union H2020-Marie Skłodowska-Curie Research Grants Scheme MSCA-IF-2018 (grant agreement no 845549: BRIFACE-Novel assessment of bridge retrofitting measures through Interface Efficiency Indices (InterFeis) using a Guided Wave-based monitoring method).

The authors would like to thank Sika AG, one of the industrial partners of the project, for their contribution to the realization of the experimental program.

Special thanks to the Democritus University of Thrace and the laboratory of Reinforced Concrete and Seismic Design of Structures for collaborating on the experimental campaign.

\section{REFERENCES}

[1] Jia-Wei Shi, Wen-Hai Cao, Zhi-Shen Wu, Effect of adhesive properties on the bond behaviour of externally bonded FRP-to-concrete joints. Composites Part B: Engineering, $177,2019$.

[2] EN1504-4:2004, Products and systems for the protection and repair of concrete structures - Definitions, requirements, quality control and evaluation of conformity - Part 4: Structural bonding, European Committee for Standardization.

[3] T. L. Attard, Toughened carbon-fiber reinforced epoxy via isophorone diisocyanate amine surface modification. Polymer, 191, 122268, 2020.

[4] Y. Kasper, M. Albiez, T. Ummenhofer, C. Mayer, T. Meier, F. Choffat, Y. Ciupack, H. Pasternak, Application of toughened epoxy-adhesives for strengthening of fatigue-damaged steel structures, Construction and Building Materials, Volume 275, 2021.

[5] ACI Committee 211, Standard practice for selecting proportions for normal, heavyweight, and mass concrete, $A C I$ 211.1-91, 1991.

[6] N. Su, K. C. Hsu \& H. W. Chai, A simple mix design method for self-compacting concrete, Cement and concrete research, 31(12), 1799-1807, 2001.

[7] EN 1008, Mixing Water for Concrete - Specification for Sampling, Testing and Assessing the Suitability of Water, Including Water Recovered from Processes in the Concrete Industry, as Mixing Water for Concrete, Brussels: CEN, European Committee for Standardization, 1995.

[8] G. P. van Zijl \& S. C. Paul, A novel link of the time scale in accelerated chloride-induced corrosion test in reinforced SHCC, Construction and Building Materials, 167, 15-19, 2018.

[9] C. Batuwitage, S. Fawzia, D. Thambiratnam, \& R. Al-Mahaidi, Durability of CFRP strengthened steel plate double-strap joints in accelerated corrosion environments. Composite Structures, 160,1287-1298, 2017.

[10] F. M. Mukhtar \& R. M. Faysal, A review of test methods for studying the FRP-concrete interfacial bond behavior, Construction and Building Materials, 169, 877-887, 2018.

[11] C. Carloni, T. D’Antino, L. H. Sneed \& C. Pellegrino, Three-dimensional numerical modeling of single-lap direct shear tests of FRCM-concrete joints using a cohesive damaged contact approach. Journal of Composites for Construction, 22(1), 04017048, 2018. 